Catalogues Issued

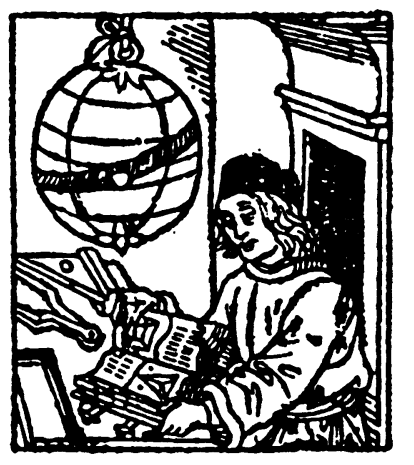

Medicine

Science

Technology

Rare Books,

Manuscripts,

\& Prints

Libraries or important single volumes purchased

Jeremy Norman \& Co., Inc.

$$
\begin{aligned}
& 442 \text { Post Street } \\
& \text { San Francisco, Calif. } 94102 \\
& {[415] 781-6402 \cdot \text { Cable: Log os }}
\end{aligned}
$$

\section{MEDICAL BOOKS}

\section{Prints * Portraits \\ Old, RARE,}

\& OUT-OF-Print

America's Largest Stock

All items are fully catalogued and classified, American and European, dating from the 15th to the 20th centuries particularly classical and unusual works, with emphasis upon history, biography, and specialized medicine. Lists issued in all fields of medicine.

We are eager to purchase small or large collections.

\section{ARGOSY BOOK STORES}

116 E. 59th St., N.Y., N.Y. 10022 , PL. 3-4455
Books on the History of Medicine and Dentistry Rare Books

We purchase collections Are you on our mailing list?

RITTENHOUSE MEDICAL BOOK STORE

1706 Rittenhouse Square, Philadelphia, Pennsylvania 19103 Area Code: 215-545-6072 